\title{
Effect of the culture system and culture technique on biochemical characteristics of Pavlova lutheri and its nutritional value for Crassostrea gigas larvae
}

\author{
E. Ponis ${ }^{1,{ }^{*}}$, G. Parisi ${ }^{1}$, J.-R. Le Coz $^{2}$, R. Robert ${ }^{3}$, G.C. Zittelli ${ }^{4}$ \& M.R. Tredici ${ }^{5}$
}

\author{
${ }^{1}$ Dipartimento di Scienze Zootecniche, Università degli Studi di Firenze, Firenze, Italy \\ ${ }^{2}$ Laboratoire de Physiologie des Invertébrés Marins, IFREMER, Plouzané, France \\ ${ }^{3}$ Laboratoire de Physiologie des Invertébrés Marins, IFREMER, Presqu'île du Vivier, Landunvez, France \\ ${ }^{4}$ Istituto per lo Studio degli Ecosistemi, CNR, Firenze, Italy \\ ${ }^{5}$ Dipartimento di Biotecnologie Agrarie, Università degli Studi di Firenze, Piazzale delle Cascine, Firenze, Italy \\ *: Corresponding author : E. Ponis, email address : $\underline{\text { mponis@usa.net }}$
}

\begin{abstract}
:
Pavlova lutheri was cultivated in carboys using batch technique and in a flat alveolar photobioreactor (FAP), using initially batch and then semi-continuous techniques. Growth and productivity of the cultures were compared and their nutritional quality was assessed by analysing their biochemical composition (gross composition, fatty acids and sterols) and by evaluating their food value for Pacific oyster (Crassostrea gigas) larvae as bispecific diet in association with Chaetoceros calcitrans forma pumilum. The highest productivity was achieved with the FAP operating in semi-continuous mode. Gross composition of $P$. lutheri was similar in all cultures, while cellular organic matter content of the microalga grown in FAP in semi-continuous mode was lower. Significant differences in fatty acid content were detected with respect to the $n-6$ polyunsaturated fatty acid fraction, which was lower in cells cultivated in the FAP in semi-continuous mode. As concerns the main individual fatty acids, docosahexaenoic acid (DHA) content was higher in cells cultivated in the photobioreactor in batch mode than in carboys. The neutral lipid fraction contained seven principal sterols and the comparison among the cultures evidenced different proportions and different patterns. No differences were observed among larvae fed diets containing P. lutheri grown in carboys or in the FAP.
\end{abstract}

Keywords: batch culture $\cdot$ biochemical composition - carboys - Crassostrea gigas - flat alveolar photobioreactors $\bullet$ Pavlova lutheri $\bullet$ semi-continuous culture

\section{Introduction}

Microalgal culture represents an essential and demanding step for spat production in bivalve hatcheries mainly because of its high cost, which may represent $50 \%$ or more of the entire hatchery management costs (Coutteau \& Sorgeloos 1992; Borowitzka 1997). In hatchery microalgae are commonly used in plurispecific diets, generally composed of one diatom and one or more flagellates to assure a better balance in essential nutrients (Coutteau \& Sorgeloos 1992; Robert \& Gérard 1999). Several studies investigated the biochemical composition of microalgae and the nutritional requirements of bivalves (Brown et al. 1989; Knauer \& Southgate 1999; Robert et al. 2004). These studies clearly indicated the fundamental role of the polyunsaturated fatty acids, with particular 
reference of eicosapentaenoic acid (20:5n-3) (EPA) and docosahexaenoic acid (22:6n-3) (DHA), and of sterols, which were also reported to be essential for oyster (Holden \& Patterson 1991). The ability of bivalves to synthesize de novo or bioconvert sterols varies among the different species, but is generally low or absent. This implies that a dietary supply of sterols is essential for bivalve growth (Teshima \& Patterson 1981; Soudant et al. 1998; Knauer et al. 1999).

The culture technique commonly used in hatcheries, i.e. batch culture carried out in carboys and cylinders or polyethylene bags, does not attain high cellular densities and requires considerable human and economic investment. Moreover, this technique does not ensure complete control of the quality of microalgal biomass, which may, accordingly, fluctuate significantly between batches (Robert \& Trintignac 1997). An attractive alternative to traditional culture systems is represented by high-performance photobioreactors (Tredici 2004). These closed systems, characterized by high surface-to-volume ratio, allow higher control of the major parameters that influence growth and nutritional quality of the cultured microalgae, minimize contamination and allow to reach high cell concentrations and volumetric productivities. The flat alveolar photobioreactor (FAP), developed in the late 1980s (Tredici et al. 1991), is constructed from 1.6-cm thick Plexiglas alveolar sheets. The FAP exhibits a high surface to volume ratio $\left(80 \mathrm{~m}^{-1}\right)$ and allows a good control of growth parameters $(\mathrm{pH}$, pO2, temperature and light intensity). This photobioreactor has been tested for cultivation of several microalgal species of interest for aquaculture, including $P$. lutheri, achieving volumetric productivities up to 10-20 times higher than those attained using traditional systems, depending on selected species and culture conditions (Tredici et al. 1996; Chini Zittelli et al. 2000; Ponis et al. 2003).

Pavlova lutheri, one of the most commonly used species in mollusc hatcheries (Chrétiennot-Dinet et al. 1986; Coutteau \& Sorgeloos 1992; Robert \& Gérard 1999; Helm et al. 2004) is characterized by high content of EPA and DHA (Brown et al. 1997; Robert et al. 2004), which are essential for marine animals (Kanazawa et al. 1979). Moreover, this microalga contains high quantities of sterols and shows a large diversity in sterol composition (Soudant et al. 1998; Robert et al. 2004). The food value of $P$. lutheri for larval and postlarval stages of the Pacific oyster (Crassostrea gigas) has been widely investigated (Walne 1970; Langdon \& Waldock 1981; Enright et al. 1986; Min et al. 1995; Thompson et al. 1996; Ponis et al. 2003). This alga generally exhibits poor value for the cupped oyster when used as single diet but positive effects have been reported for its use in multispecific diets, in association with one or more diatoms.

The aim of this work was to evaluate the influence of the culture system (production in batch using glass carboys versus production in batch using a FAP) and of the culture technique (batch mode versus semi-continuous mode, in FAP) on growth, productivity, biochemical composition and nutritional value of $P$. lutheri. To that end, the gross composition, as well as the fatty acid and sterol contents and profile of the microalga cultured in the different conditions was analysed while the nutritional value of $P$. lutheri biomasses was concurrently estimated through feeding trials with $C$. gigas larvae.

\section{Materials and methods}

\section{Microalgal cultures}

Microalgae were obtained from IFREMER experimental hatchery of Argenton (France) and cultivated according to the standard batch culture method (Robert et al. 2004) in 10-L glass carboys. The microalgae were grown in enriched seawater (Conway medium, $1 \mathrm{~mL} \mathrm{~L}^{-1}$; Walne 1966) under continuous illumination ( $150 \mu \mathrm{mol}$ photons $\mathrm{m}^{-2} \mathrm{~s}^{-1}$ )at a temperature of 20-22 C and a salinity of $33-34 \mathrm{~g}$ $\mathrm{L}^{-1}$. Seawater was natural and 1-mm filtered and UV treated. For the diatom, the salinity was reduced to 
$25 \mathrm{~g} \mathrm{~L}^{-1}$ by addition of distilled water and sodium metasilicate $\left(40 \mathrm{mg} \mathrm{L}^{-1}\right)$ provided as silica source. Cultures were mixed by bubbling air enriched with $2 \% \mathrm{CO}_{2}$ (volume) which maintained the $\mathrm{pH}$ in a range of 7.5-8.1.

For the experiments, $P$. lutheri was cultivated in a 4.1-L FAP under the culture conditions already described, except light intensity which was $125 \mu \mathrm{mol}$ photons $\mathrm{m}^{-2} \mathrm{~s}^{-1}$. During the first 7 days, the culture was operated in batch; thereafter, once the culture reached a density of about $1.9 \mathrm{~g}$ dry weight $\mathrm{L}^{-1}$, a semi-continuous harvesting regimen was applied (dilution rate: 0.31 day $^{-1}$ ). In order to prevent nitrogen and phosphorus limitation, $\mathrm{NaNO}_{3}$ and $\mathrm{NaH}_{2} \mathrm{PO}_{4}$ were supplied regularly, according to microalgal growth.

\section{Feeding trials}

C. gigas broodstock, obtained from various French oyster cultivation areas, were conditioned in the IFREMER Laboratory of Brest according to the technique described by Robert \& Gérard (1999). Embryonic development occurred in 250-L cylinders, at a density of 10 embryos $\mathrm{mL}^{-1}$. After $48 \mathrm{~h}$ from fertilization, straight-hinged larvae were collected, counted, retained on a 60- $\mu \mathrm{m}$ mesh sieve and then dispensed at a density of 5 larvae $\mathrm{mL}^{-1}$ into $2 \mathrm{~L}$ glass beakers, each containing 1.8- $\mathrm{L}$ of $1 \mu \mathrm{m}$ filtered seawater $\left(20{ }^{\circ} \mathrm{C}\right.$ temperature and $33-34 \mathrm{~g} \mathrm{~L}^{-1}$ salinity). In order to limit bacterial contamination, chloramphenicol was added at $4 \mathrm{mg} \mathrm{L}^{-1}$.

During the 14-day feeding trial, $P$. lutheri was tested in mixed diets, each running in triplicate, in association with the diatom $C$. calcitrans forma pumilum. Indeed, single haptophyte diets does not allow sufficient $C$. gigas larval growth and most often high mortality occurs in such monospecific feeding experiment, leading to bias resulting in data difficult to interpret. Chaetoceros calcitrans f. pumilum is a very high nutritional diatom for $C$. gigas (Robert et al. in press) and, when used in mixtures, cautions must be taken to do not mask the effect of the other microalgae. To point out the food value of $P$. lutheri produced in carboys or FAP in batch or in semi-continuous cultures, without diatom overlap the bispecific diets were accordingly composed of $80 \%$ flagellate and $20 \%$ diatom, based on cellular volume. Two different experimental diets were compared: (i) $P$. lutheri produced in FAP $+C$. calcitrans $f$. pumilum $(\mathrm{PF}+\mathrm{C}$ ); (ii) $P$. lutheri produced in carboys $+C$. calcitrans $\mathrm{f}$. pumilum $(\mathrm{PC}+\mathrm{C})$; during the first week the FAP was operated in batch mode (diet $\mathrm{PFb}+\mathrm{C}$ ), while a semi-continuous regimen was applied during the second week (PFsc $+\mathrm{C}$ ). Moreover, two controls were included in the feeding trial, a negative control (unfed larvae) and a positive control (C. calcitrans f. pumilum as a single diet).

At each seawater renewal, every other day, the larvae were fed on the basis of $100 P$. lutheri cell equivalents $\mu^{-1}$ so that all the diets were equivalent in feed volume. Based on microalgae cellular volume, one cell of $P$. lutheri was considered equivalent to two cells of $C$. calcitrans f. pumilum. Bispecific diets contained $80 \%$ of $P$. lutheri and $20 \%$ of $C$. calcitrans f. pumilum.

\section{Analytical procedures}

Culture growth was daily estimated by measurement of cell number, using a Malassez haemocytometer (Batailler Labo, Treillères, France) and by measurement of dry biomass concentration. For dry weight determinations, triplicate culture samples $(1-15 \mathrm{~mL}$, depending on cell density) were filtered through preweighed 47-mm Whatman GF/C glass-fibre filters. The filtered cells were washed with $0.5 \mathrm{M}$ ammonium formate $(25 \mathrm{~mL})$ and then dried at $105{ }^{\circ} \mathrm{C}$ to constant weight $(6-8 \mathrm{~h})$. Samples for biochemical composition of $P$. lutheri were collected in duplicate each second day during the first week (three samples) and each third day during the second week (two samples). At each time a volume containing about $200 \times 10^{6}$ cells was collected on precombusted $\left(450{ }^{\circ} \mathrm{C}\right) 25 \mathrm{~mm}$-Whatman GF/F glass-fibre filters, and stored at $-20^{\circ} \mathrm{C}$ for a period of up to 3 months prior to analysis. Filters were then 
homogenized by grinding in $1.5 \mathrm{~mL}$ of distilled water within a Potter homogenizer for $2 \mathrm{~min}$. Aliquots of the homogenate were analysed separately for protein (Lowry et al. 1957), carbohydrate (Dubois et al. 1956) and lipid (Bligh \& Dyer 1959). The total organic matter was calculated as the sum of protein, lipid and carbohydrate.

For fatty acid and sterol analyses, total lipids were extracted in chloroform-methanol according to Folch et al. (1957). Fatty acids were analysed after transesterification with BF3 according to Marty et al. (1992) using a Hewlett-Packard HP6890 gas-chromatograph equipped with a JW DB-WAX capillary column (30 m x $0.25 \mathrm{~mm}, 0.25 \mathrm{~mm}$ film thickness), hydrogen as carrier gas and 23:0 as an internal standard. Sterols were analysed using the method described by Soudant et al. (2000) after transesterification with sodium methoxide (MeONa; Eder et al. 1992) in a Chrompack CP 9002 gas chromatograph (Chrompack International BV, Middleburg, The Netherlands) equipped with a Restek Rt X 65 fused silica capillary column (Restek, Bellefonte, PA, USA) (15 m x $0.25 \mathrm{~mm}, 0.25 \mu \mathrm{m}$ film thickness) using hydrogen as carrier gas and cholestane as internal standard. The sterols were identified by comparison of their retention time with standards and by their GC/MS spectra (Carlo-Erba model 5160 HRGC (Carlo Erba Strumentazione, Milan, Italy) coupled to a mass spectrometer Nermag R10-10H).

Larvae were sampled at the beginning and at the end of the trial (day 1 and day 14, respectively) and at day 7, which corresponds to the end of the batch phase in the FAP. At each time, at least 200 animals from each replicate were collected in order to determine larval growth and mortality. Larval growth was determined by measuring the major shell length, defined as the antero-posterior axis parallel to the hinge; for this purpose an image analysis technique, using the Image SXM processing software (NiH), was employed (Barret, 2006). Larval mortality was estimated by counting the translucent larval shells under microscope, the survival rate corresponding to the complement of the mortality percentage.

\section{Statistics}

Biochemical data were analysed by the nonparametrical Mann-Whitney U-test (type of culture). Growth and survival were analysed using one-way ANOVA while significant differences $(P<0.05)$ between dietary treatments were determined using Scheffé's multiple comparison test. Data concerning survival percentage were transformed (arcsin square root of xi $100^{-1}$ ) before statistical analysis, performed under Statview software version 5 (SAS software, 1998).

\section{Results}

Productivity and biochemical composition of P.lutheri cultivated in carboys and in a flat alveolar photobioreactor Figure 1 shows the growth curves of $P$. lutheri cultivated in carboys and in the FAP. The culture cultivated in the photobioreactor attained a cell concentration significantly higher with respect to

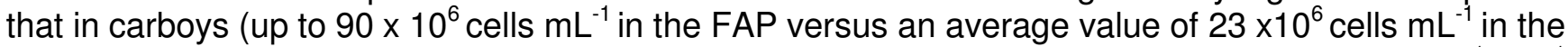
carboys). The volumetric productivity of $P$. lutheri in the FAP was on average $0.25 \mathrm{~g}_{\text {dry }}$ weight $\mathrm{L}^{-1}$ day $^{-1}$ (corresponding to $8.4 \times 10^{6}$ cells $\mathrm{mL}^{-1}$ day $^{-1}$ ) during the batch growth phase and increased to $0.53 \mathrm{~g}$ dry weight $\mathrm{L}^{-1}$ day $^{-1}$ (corresponding to $20.8 \times 10^{6}{\mathrm{cells} \mathrm{mL}^{-1} \text { day }}^{-1}$ ) when a semi-continuous regimen was adopted. In the carboys, the average volumetric productivity was $0.10 \mathrm{~g}$ dry weight $\mathrm{L}^{-1} \mathrm{day}^{-1}$, corresponding to $3.3 \times 10^{6}$ cells $\mathrm{mL}^{-1}$ day ${ }^{-1}$. In this study, the FAP has been profitable to produce $P$. lutheri, achieving volumetric productivities 2.5 times higher than those attained in standard carboy cultures, when used in batch mode, and five times higher when used semi-continuously. The biochemical composition of $P$. lutheri cultivated in carboys and in the FAP is reported in Table 1 . The different cultures did not show any considerable change in the gross biochemical composition. Protein was the major organic component (550-600 $\mu \mathrm{g} \mathrm{g}^{-1}$ of organic matter), followed by lipid (280-305 $\mu \mathrm{g} \mathrm{g}^{-1}$ ) and carbohydrate $\left(96-130 \mu \mathrm{g} \mathrm{g}^{-1}\right)$. No significant differences in terms of cellular organic matter content were found in $P$. lutheri cultivated in carboys or in the FAP in batch mode (30.6 and $29.5 \mathrm{pg} \mathrm{cell}^{-1}$ for 
carboys and FAP, respectively). The change from batch to semi-continuous regimen in the FAP did not influence significantly the cell gross composition, but a lower organic matter content was observed (25.4 versus $29.5 \mathrm{pg} \mathrm{cell}^{-1}$ ).

The amount of saturated, monounsaturated, polyunsaturated and of n-3 PUFA fractions, as well as the total fatty acid content, did not differ between cultures (Table 2). The major fatty acids found were the saturated 16:0, the mono-unsaturated 16:1n-7 and the n-3 polyunsaturated EPA and DHA. In all the cultures these four fatty acids accounted for more than $72 \%$ of the total fatty acids, with EPA and DHA representing, on average, 25 and $10 \%$ of the total fatty acid content, respectively. The content of these polyunsaturated fatty acids did not differ significantly among cultures, except for DHA content, which resulted higher in $P$. lutheri cultivated in the FAP in batch mode. As far as the other fatty acids are concerned, the comparison between $P$. lutheri cultures evidenced some significant differences: with respect to the cultures grown in batch (FAP versus carboys), $P$. lutheri grown in carboys exhibited a higher content in 18:1n-7 and a lower content in 18:3n-3 and in 22:6n-3; a higher content of 18:1n-7, $18: 2 n-6,22: 5 n-6$ and of the n-6 polyunsaturated fatty acid fraction and a lower content of $18: 3 n-3$ were observed in the biomasses produced in carboys compared with those obtained with FAP operating in semi-continuous; in the comparison between cultures produced in FAP, batch cultures exhibited higher content of 18:2n-6, 22:6n-3 and of the n-6 polyunsaturated fatty acid fraction.

Sterol pattern contained seven different sterols, of which four (stigmasterol, $4 \alpha$-methylporiferasterol, $\beta$-sitosterol and methylpavlovol) represented more than $85 \%$ of the total sterols detected (Table 3 ). The proportion of the two species-specific sterols, methylpavlovol and ethylpavlovol, resulted significantly higher in $P$. lutheri cultivated in carboys, while a lower content of $\beta$-sitosterol was observed in this latter. The comparison between $P$. lutheri produced in batch showed a lower content in desmosterol and in 4a-methylporiferasterol in the biomass produced in carboys. As concerns the culture cultivated in FAP, desmosterol proportion was higher in the microalga produced in batch.

Nutritional value for $C$. gigas larvae

At the end of the first week (Table 4), no significant differences among bispecific diets were detected, although larvae fed PC $+\mathrm{C}$ exhibited a slightly higher size $(104.6 \mu \mathrm{m})$ compared with those fed PFb $+\mathrm{C}$ $(99.5 \mu \mathrm{m})$. Nevertheless, larvae fed solely $C$. calcitrans f. pumilum showed the highest shell length $(114.3 \mu \mathrm{m})$. During the second week of the trial, when a semi-continuous regimen was adopted to produce $P$. lutheri in the FAP, no significant differences were detected among bispecific diets, while the diet based solely on the diatom led to lower performances than that observed with the diet PC $+\mathrm{C}$.

During the first week survival was $\geq 95 \%$, without significant differences among diets and did not change significantly at the end of the second week, except for unfed larvae that only exhibited $72 \%$ of survival.

\section{Discussion}

Microalgae culture systems used in hatcheries should satisfy the following main requirements: (i) be inexpensive and easy to set-up, (ii) ensure the continuous availability of cultures, (iii) allow the cultivation of different species simultaneously, (iv) be adaptable to rapid expansions or reductions in culture capacity as a consequence of different requirements of cultured animals and ( $\mathrm{v}$ ) prevent contamination (Ukeles 1973). The use of a fully controlled photobioreactor to the mass cultivation of marine phytoplankton for aquaculture appears accordingly of great interest (Tredici 2004).

Our results on cell concentration in the two systems were similar to those reported by Ponis (2002) with $P$. lutheri cultivated in the FAP under similar conditions and for a longer period. Significantly higher productivities (up to $1.2 \mathrm{~g} \mathrm{~L}^{-1}$ day $^{-1}$ ) were reported for $P$. lutheri cultures grown in FAP in semi-continuous mode at a higher light intensity (Tredici et al. 1996).

It is generally difficult to compare the biochemical composition of microalgae between different studies, the biochemical composition of the microalgal biomass being strictly dependent on factors such as light quality and intensity, temperature, photoperiod, nutrient availability, growth phase and harvesting 
regimen (Millamena et al. 1990; Renaud et al. 1991; Thompson \& Harrison 1992; Brown et al. 1993; Thompson et al. 1993; Carvalho \& Malcata 2000). For example, the haptophytes $P$. lutheri and Isochrysis galbana (clone T-Iso) contained two to four times more carbohydrate in the stationary phase (Brown et al. 1993). The content of essential n-3 polyunsaturated fatty acids (n-3 PUFAs) was also higher in the stationary phase than in the logarithmic phase of growth in P. lutheri (Dunstan et al. 1993). In this study the biochemical composition of $P$. lutheri was only slightly affected by the different culture systems and culture techniques adopted. The macronutrient levels obtained indicated an appropriate composition, as, in general, larval molluscs require 300 to $600 \mu \mathrm{g} \mathrm{g}^{-1}$ protein in the diet for an adequate growth (Brown et al. 1989). During the second week of cultivation in the FAP, a significant decrease in $P$. lutheri cell weight was observed, probably as a consequence of the semi-continuous harvesting regimen applied, which modified the growth conditions in the photobioreactor (availability of fresh nutrients, different light regimen). The cellular size of microalgae is known to be strictly dependent on environmental factors such as light quality and intensity and nutrient status (Witt et al. 1981; Renaud et al. 1991; Tzovenis et al. 2003).

Whatever the type of production (batch or semi-continuous, carboys or FAP), the total quantity and pattern of fatty acids of $P$. lutheri were similar to those reported for the same microalga by Dunstan et al. (1993). No differences between cultures were detected in terms of total fatty acid content or amount of fatty acids for each fraction while, as concerns the single fatty acids DHA level in the FAP operating in batch was significantly higher; this fact might be related to different culture conditions. The modulation of fatty acid profiles in response to different light regimes or nutrient status was described for haptophytes by Tzovenis et al. (1997) and Carvalho \& Malcata (2000). The importance of the sterols for bivalve metabolism has been already pointed out (Holden \& Patterson 1991; Soudant et al. 2000; Kanazawa 2001).

The sterol pattern of $P$. lutheri grown in carboys and in FAP was similar to the pattern described by Soudant et al. (1998). This microalga contained seven principal sterols, including methylpavlovol and ethylpavlovol, which are specific of the Pavlovales family (Véron et al. 1996) and belong, in association with $4 \alpha$-methylporiferasterol, to the 4-methylsterols group. A study carried out by Knauer et al. (1999) on the assimilation of dietary phytosterols by $C$. gigas spat showed that these sterols were poorly incorporated by the animals. Similar results have been obtained by Soudant et al. (1998) on Pecten maximus larvae. In this study the $4 \alpha$-methylsterols represented up to the $50 \%$ of the total sterols detected, this may partly explain the inadequacy of $P$. lutheri to sustain adequate growth of Pacific oyster larvae when used as a single component of the diet (Ponis et al. 2003).

These results, showing differences in the proportion of sterols, were not unexpected because of the fact that, as with other biochemical components, sterols are influenced by factors such as temperature, light intensity and regime, growth phase and, in the case of semi-continuous cultures, renewal rate (Ballantine et al. 1979; Brown et al. 1989; Fabregas et al. 1997).

Microalgal strains are commonly used in mollusc cultures in plurispecific diets (generally one diatom and one or more flagellate), to ensure a better balance of the nutritional components (Robert \& Trintignac 1997). Accordingly, the food value of $P$. lutheri biomasses produced in the different systems and conditions was evaluated in bispecific diets, in association with $C$. calcitrans f. pumilum, using as controls a group of unfed larvae and a monospecific diet exclusively based on that diatom. During the first week of the feeding trial no significant differences were detected among the two bispecific diets; however, these values were lower than that recorded when using the diatom solely. During the second week of the trial, when FAP operated in semi-continuous mode, the two bispecific diets led to similar results, significantly higher to the diet based solely on the diatom. Such differences might be explained by a preferential uptake of that small diatom by young larvae, as recently observed (Robert et al. in press).

Chaetoceros calcitrans f. pumilum is known to be a valuable microalga for $C$. gigas larvae, leading to good growth performances (Helm \& Bourne 2004). Nevertheless, this microalga is deficient in DHA (Volkman et al. 1989) and its use as sole component of the diet should be verified over a longer period. Thus studies carried out with $P$. maximus demonstrated that larvae fed solely $C$. calcitrans allowed good 
growth but failed to complete the metamorphosis process (Delaunay et al. 1993; Soudant et al. 1998). In conclusion, the comparison among $P$. lutheri cultures produced with different systems and harvesting regimes evidenced the good performances of the FAP operating in semi-continuous mode in terms of volumetric productivity, while both biochemical composition and nutritional values of the produced biomasses exhibited only slight differences. The FAP, which operates under strictly controlled conditions, resulted effective for the production of highly concentrated microalgal biomass and was proven to be reliable for $P$. lutheri culture in semi-continuous mode, maintaining high daily productivity.

\section{References}

Ballantine, J.A., Lavis, A. \& Morris, R.J. (1979) Sterols of the phytoplankton - effects of illumination and growth stage. Phytochemistry, 8, 1459-1466.

Barret, S.D. (2006) Image SXM, http://www.ImageSXM.org.uk

Bligh, E.G. \& Dyer, W.T. (1959) A method of total lipid extraction and purification. Can. J. Biochem. Physiol., 77, 911-917.

Borowitzka, M.A. (1997) Microalgae for aquaculture: opportunities and constraints. J. Appl. Phycol., 8, 393-401.

Brown, M.R., Jeffrey, S.W. \& Garland, C.D. (1989) Nutritional Aspects of Microalgae Used in Mariculture: a Literature Review. Csiro Marine Laboratories Report 205, Csiro, Hobart, Tasmania. 43 pp.

Brown, M.R., Garland, C.D., Jeffrey, S.W., Jameson, I.D. \& Leroi, J.M. (1993) The gross and amino acid compositions of batch and semi-continuous cultures of Isochrysis sp. (clone T. ISO), Pavlova lutheri and Nannochloropsis oculata. J. Appl. Phycol., 5, 285-296.

Brown, M.R., Volkman, J.K. \& Dunstan, G.A. (1997) Nutritional properties of microalgae for mariculture. Aquaculture, 151, 315-331.

Carvalho, A.P. \& Malcata, F.X. (2000) Effect of culture media on production of polyunsaturated fatty acids by Pavlova lutheri. Cryptogamie, 21, 59-71.

Chini Zittelli, G., Pastorelli, R. \& Tredici, M.R. (2000) A modular flat panel photobioreactor (MFPP) for indoor mass cultivation of Nannochloropsis sp. under artificial illumination. J. Appl. Phycol., 12, 521-526.

Chrétiennot-Dinet, M.J., Robert, R. \& His, E. (1986) Utilisation des « algues-fourrage » en aquaculture. Ann. Biol., 25, 97-116.

Coutteau, P. \& Sorgeloos, P. (1992) The use of algal substitutes and the requirement for live algae in hatchery and nursery rearing of bivalve molluscs: an international survey. J. Shellfish Res., 11, 467476.

Delaunay, F., Marty, Y., Moal, J. \& Samain, J.-F. (1993) The effect of monospecific algal diets on growth and fatty acid composition of Pecten maximus (L.) larvae. J. Exp. Mar. Biol. Ecol., 173, 163- 179.

Dubois, M., Gilles, K.A., Hamilton, J.K., Rebers, P.A. \& Smith, F. (1956) Colorimetric method for determination of sugars and related substances. Anal. Chem., 28, 350-356.

Dunstan, G.A., Volkman, J.K., Barret, S.M. \& Garland, C.D. (1993) Changes in the lipid composition and maximisation of the polyunsaturated fatty acid content of three microalgae grown in mass culture. J. Appl. Phycol., 5, 71-83.

Eder, K., Reichlmayr-Lais, A.M. \& Kirchgessne, M. (1992) Simultaneous determination of amounts of major phospholipid classes and their fatty acid composition in erythrocyte membranes using high-performance liquid chromatography and gas chromatography. J. Chromatogr., 598, 33-42.

Enright, C.T., Newkirk, G.F., Craige, G.F. \& Castell, J.D. (1986) Growth of juvenile Ostrea edulis L. fed Chaetoceros gracilis Schütt of varied chemical composition. J. Exp. Mar. Biol. Ecol., 96, 15-26.

Fábregas, J., Arán, E., Morales, E.D., Lamela, T. \& Otero, A. (1997) Modification of sterol concentration in marine microalgae. Phytochemistry, 7, 1189-1191.

Folch, J., Lees, M. \& Sloane Stanley, G.H. (1957) A simple method for the isolation and purification of total lipids from animal tissues. J. Biol. Chem., 266, 497-509. 
Helm, M.M., Bourne, N. \& Lovatelli, A. (2004) Hatchery Culture of Bivalves. A Practical Manual. FAO Fisheries Technical Paper 471, pp. 177.

Holden, M.J. \& Patterson, G.W. (1991) Absence of sterol biosynthesis in oyster tissue culture. Lipids, 26, 81-82.

Kanazawa, A. (2001) Sterols in marine invertebrates. Fish. Sci., 67, 997-1007.

Kanazawa, A., Teshima, S. \& Ono, K. (1979) Relationships between the essential fatty acid requirement of aquatic animals and their capacity for bioconversion of linoleic acid to highly unsaturated fatty acid. Comp. Biochem. Physiol., 63B, 295- 298.

Knauer, J. \& Southgate, P.C. (1999) A review of the nutritional requirements of bivalves and the development of alternative and artificial diets for bivalve aquaculture. Rev. Fish. Sci., 7, 241- 280.

Knauer, J., Barrett, S.M., Volkman, J.K. \& Southgate, P.C. (1999) Assimilation of dietary phytosterols by Pacific oyster Crassostrea gigas spat. Aquac. Nutr., 5, 257-266.

Langdon, C.J. \& Waldock, M.J. (1981) The effect of algal and artificial diets on the growth and fatty acid composition of Crassostrea gigas spat. J. Mar. Biolog. Assoc. U.K., 61, 431-448.

Lowry, O.H., Rosebrough, N.J., Farr, A.L. \& Randall, R.J. (1957) Protein measurement with the folin phenol reagent. J. Biol. Chem., 193, 265-275.

Marty, Y., Delaunay, F., Moal, J. \& Samain, J.F. (1992) Changes in the fatty acid composition of Pecten maximus (L.) during larval development. J. Exp. Mar. Biol. Ecol., 163, 221-234.

Millamena, O.M., Aujero, E.J. \& Borlongan, I.G. (1990) Techniques on algae harvesting and preservation for use in culture and as larval food. Aquac. Eng., 9, 295-304.

Min, K.S., Chang, Y.J., Park, D.W., Jung, C.G., Kim, D.H. \& Kim, G.H. (1995) Studies on rearing conditions for mass seedling production in Pacific oyster, Crassostrea gigas (Thunberg). Bull. Natl Fish. Res. Dev. Agency (Korea), 49, 91-111.

Ponis, E. (2002) Production, conservation de microalgues concentrées: dé termination de leur valeur nutritionnelle sur les larves et juvéniles de Crassostrea gigas. PhD Thesis, Universite' de la Bretagne Occidentale, Universita` degli Studi di Firenze, France, Italy, 130 pp.

Ponis, E., Robert, R., Parisi, G. \& Tredici, M. (2003) Assessment of the performance of Pacific oyster (Crassostrea gigas) larvae fed with fresh and preserved Pavlova lutheri concentrates. Aquac. Int., 11, 69-79.

Renaud, S.M., Parry, D.L., Luong-Van, T., Kuo, C., Padovan, A. \& Sammy, N. (1991) Effect of light intensity on the proximate biochemical and fatty acid composition of Isochrysis sp. and Nannochloropsis oculata for use in tropical aquaculture. J. Appl. Phycol., 3, 43-53.

Robert, R. \& Ge' rard, A. (1999) Bivalve hatchery techniques: current situation for the oyster Crassostrea gigas and the scallop Pecten maximus. Aquat. Living Resour., 12, 121-130.

Robert, R. \& Trintignac, P. (1997) Substitutes for live microalgae in mariculture: a review. Aquat. Living Resour., 10, 315-327.

Robert, R., Chreétiennot-Dinet, M.J., Kaas, R. (2004) Amélioration des productions phytoplanctoniques en écloserie de mollusques: caractérisation des microalgues fourrage. Report Ifremer DRV/RA/RST/LPI/2004-2005, pp. 150.

Robert, R., Rico-Villa, B. \& Mingant, C. (in press) Influence of sole and plurispecific diets on larval consumption and development of Pacific oyster Crassostrea gigas (Thunberg). Oyster Res. Inst. News.

Soudant, P., Le Coz, J.R., Marty, Y., Moal, J. \& Robert, R. (1998) Incorporation of microalgae sterols by scallop Pecten maximus (L.) larvae. Comp. Biochem. Physiol., 119A, 451-457.

Soudant, P., Van Sanles, M., Quéré C., Le Coz, J.R., Marty, Y., Moal, J., Samain, J.F. \& Sorgeloos, P. (2000) The use of lipid emulsion for sterol supplementation of the Pacific oyster Crassostrea gigas. Aquaculture, 184, 315-326.

Teshima, S. \& Patterson, G.W. (1981) Sterol biosynthesis in the oyster Crassostrea virginica. Lipids, 16, 234-239.

Thompson, P.A. \& Harrison, P.J. (1992) Effects of monospecific algal diets of varying biochemical composition on the growth and survival of Pacific oyster (Crassostrea gigas) larvae. Mar. Biol., 113, 645-654. 
Thompson, P.A., Guo, M.X. \& Harrison, P.J. (1993) The influence of the irradiance on the biochemical composition of three phytoplankton species and their nutritional value for larvae of the Pacific oyster (Crassostrea gigas). Mar. Biol., 117, 259-268.

Thompson, P.A., Guo, M.X. \& Harrison, P.J. (1996) Nutritional value of diets that vary in fatty acid composition for larval Pacific oysters (Crassostrea gigas). Aquaculture, 143, 379-391.

Tredici, M.R. (2004) Mass production of microalgae: photobioreactors. In: Handbook of Microalgal Cultures, Biotechnology and Applied Phycology (Richmond, A. ed.), pp. 178-214. Blackwell, Oxford, U.K.

Tredici, M.R., Carlozzi, P., Chini Zittelli, G. \& Materassi, R. (1991) A vertical alveolar panel (VAP) for outdoor mass cultivation of microalgae and cyanobacteria. Bioresour. Technol., 38, 153-159.

Tredici, M.R., Chini Zittelli, G. \& Montaini, E. (1996) Cold-pre-servation of microalgae aquaculture feeds. Proceedings of Refrigeration and Aquaculture, Commission C2 of the IIR. International Institute of Refrigeration, Bordeaux, pp. 25-32.

Tzovenis, I., De Pauw, N. \& Sorgeloos, P. (1997) Effect of different light regimes on the docosahexaenoic acid (DHA) content of Isochrysis aff. galbana (clone T-Iso). Aquac. Int., 5, 489-507.

Tzovenis, I., De Pauw, N. \& Sorgeloos, P. (2003) Optimisation of T-Iso biomass production rich in essential fatty acids. I Effect of different light regimes on growth and biomass production. Aquaculture, 216, 203-222.

Ukeles, R. (1973) Continuous culture-a method for the production of unicellular algal foods. In: Handbook of Phycological Methods (Stein, J.H. ed.), pp. 233-254. Cambridge University Press, New York.

Véron, B., Dauguet, J.C. \& Billard, C. (1996) Sterolic biomarkers in marine phytoplankton. Free and conjugated sterols of Pavlova lutheri (Haptophyta). Eur. J. Phycol., 31, 211-215.

Volkman, J.K., Jeffrey, S.W., Nicolas, P.D., Rogers, G.I. \& Garland, C.D. (1989) Fatty acid and lipidic composition of 10 species of microalgae used in mariculture. J. Exp. Mar. Biol. Ecol., 128, 219-240.

Walne, P.R. (1966) Large scale culture of larvae Ostrea edulis L. Fish Invest., II 25, 1-52.

Walne, P.R. (1970) Studies on the food value of nineteen genera of algae to juvenile bivalves of the genera Ostrea, Crassostrea, Mercenaria and Mytilus, Ministry of Agriculture Fisheries and Food (U.K.). Fish. Invest., 26, 62.

Witt, U., Koske, P.H., Kuhlmann, D., Lenz, J. \& Nellen, W. (1981) Production of Nannochloropsis spec. (Chlorophyceae) in large scale outdoor tanks and its use as a food organisms in marine aquaculture. Aquaculture, 23, 171-181. 


\section{Tables}

Table 1 Gross composition of $P$. lutheri produced in carboys $(C)$ and in the flat alveolar photobioreactor in batch $\left(F_{\mathrm{B}}\right)$ and in semi-continuous mode $\left(\mathrm{F}_{\mathrm{SC}}\right)$.

\begin{tabular}{lccccc}
\hline & $\mathrm{F}_{\mathrm{B}}$ & $\mathrm{F}$ & $\mathrm{C}$ & $\mathrm{F}_{\mathrm{B} \text { versus }} \mathrm{F}_{\mathrm{SC} \text { B versus }} \mathrm{C}$ & $\mathrm{F}_{\text {versus }} \mathrm{C}$ \\
\hline Protein $\left(\mu \mathrm{g} \mathrm{g}^{-1}\right)$ & $598.4 \pm 118.3$ & $553.5 \pm 97.5$ & $580.2 \pm 63.1$ & \\
& & & & \\
Carbohydrate $\left(\mu \mathrm{g} \mathrm{g}^{-1}\right)$ & $96.0 \pm 45.2$ & $120.6 \pm 89.0$ & $129.9 \pm 71.2$ & \\
& & & & \\
Lipid $\left(\mu \mathrm{g} \mathrm{g}^{-1}\right)$ & $305.6 \pm 45.1$ & $299.6 \pm 30.6$ & $282.4 \pm 45.8$ & $*$ \\
Organic matter $\left(\mathrm{pg} \mathrm{cell}^{-1}\right)$ & $29.5 \pm 2.6$ & $25.4 \pm 1.3$ & $30.6 \pm 4.3$ & $*$ \\
\hline
\end{tabular}

Compositional data are expressed as $\mu \mathrm{g} \mathrm{g}^{-1}$ of organic matter while the total organic matter content is expressed per cell $\left(p g\right.$ cell $\left.^{-1}\right)$. Mean \pm SD values $(n \geq 4)$ are shown

${ }^{*} P<0.05$ 
Table 2 Fatty acid composition of $P$. lutheri produced in carboys $(C)$ and in the flat alveolar photobioreactor in batch $\left(F_{\mathrm{B}}\right)$ and in semi-continuous mode $\left(\mathrm{F}_{\mathrm{SC}}\right)$.

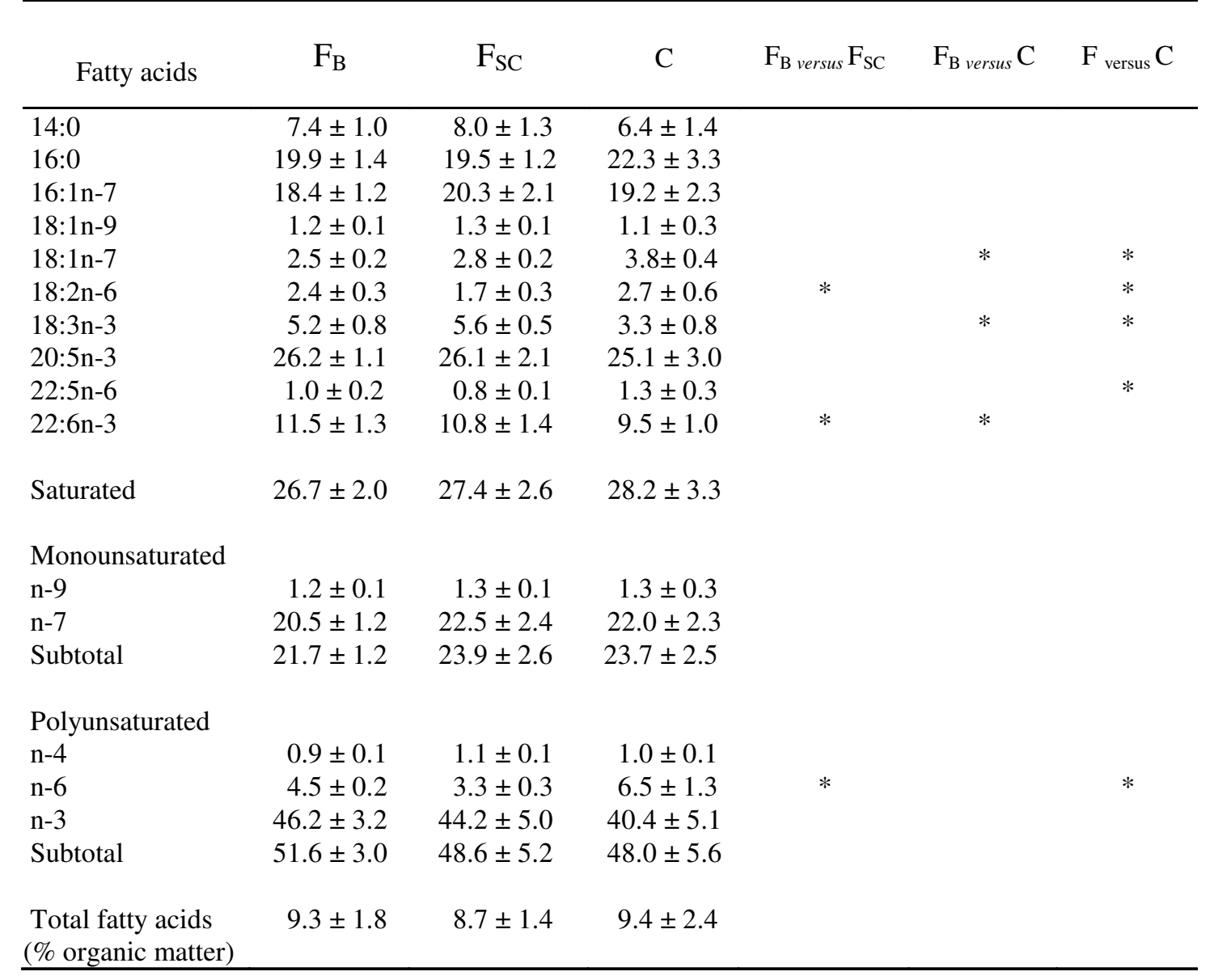

Compositional data are expressed as percentage of total fatty acids, while the total content is expressed as percentage of organic matter. Mean \pm SD values $(n \geq 4)$ are shown.

${ }^{*} P<0.05$

Other fatty acids $(18: 0,22: 0,24: 0,16: 1 n-9,16: 1 n-13,20: 1 n-9,20: 1 n-7,16: 2 n-7,16: 2 n-6,16: 2 n-$ 4, 16:3n-4, 16:3n-3, 18:2n-4, 18:3n-6, 18:4n-3, 20:2n-6, 20:3n-6, 20:4n-6, 20:4n-3, 21:5n-3, $22: 4 n-6,22: 5 n-3)$, found in minor amount have been included in the composite fractions but not shown in the table. 
Table 3 Sterol composition (expressed as percentage of total sterols; mean \pm $\mathrm{SD} ; \mathrm{n} \geq 4$ ) of $P$. lutheri biomass produced in carboys (C) and in the flat alveolar photobioreactor in batch $\left(F_{B}\right)$ and in semi-continuous mode $\left(F_{S C}\right)$

\begin{tabular}{lrrrccc}
\hline \multicolumn{1}{c}{ Sterols } & \multicolumn{1}{c}{$\mathrm{F}_{\mathrm{B}}$} & \multicolumn{1}{c}{$\mathrm{F}_{\mathrm{SC}}$} & $\mathrm{C}$ & $\mathrm{F}_{\mathrm{B} \text { versus }} \mathrm{F}_{\mathrm{SC}}$ & $\mathrm{F}_{\mathrm{B} \text { versus }} \mathrm{C}$ & $\mathrm{F}_{\text {versus }} \mathrm{C}$ \\
& \multicolumn{7}{c}{} & & & & \\
& & & & & \\
\hline desmosterol & $2.2 \pm 0.9$ & $1.0 \pm 0.1$ & $1.2 \pm 0.3$ & $*$ & $*$ & \\
campesterol & $6.4 \pm 1.3$ & $5.6 \pm 0.2$ & $6.1 \pm 0.6$ & & & \\
stigmasterol & $16.4 \pm 0.6$ & $17.6 \pm 2.6$ & $15.8 \pm 3.6$ & & $*$ & \\
$4 \alpha$-methylporiferastenol & $20.5 \pm 1.0$ & $19.6 \pm 0.5$ & $18.2 \pm 1.6$ & & $*$ & $*$ \\
$\beta$-sitosterol & $29.9 \pm 0.8$ & $28.9 \pm 2.6$ & $22.7 \pm 3.6$ & & $*$ & $*$ \\
methylpavlovol & $21.2 \pm 0.3$ & $23.6 \pm 1.9$ & $28.6 \pm 3.3$ & & $*$ & $*$ \\
ethylpavlovol & $3.5 \pm 0.2$ & $3.7 \pm 0.3$ & $5.9 \pm 0.9$ & & $*$ & \\
\hline
\end{tabular}

$* P<0.05$

desmosterol $=$ cholesta-5-en-3 $\beta$-ol;

campesterol $=24 \alpha$-methylcholesta-5-en-3 $\beta$-ol;

stigmasterol $=24 \beta$-ethylcholesta-5,22-dien-3 $\beta$-ol;

$4 \alpha$ methylporiferastenol $=4 \alpha$-methyl-24 $\alpha$-ethylcholesta-22-en-3 $\beta$-ol;

$\beta$-sitosterol $=24 \beta$-ethylcholesta-5-en-3 $\beta$-ol;

methylpavlovol $=4 \alpha, 24 \beta$-dimethylcholestan-3 $\beta, 4 \beta$-diol;

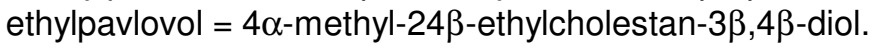


Table 4 Shell length (mean \pm SD; $n=200$ per replicate) and survival rate (mean $\pm \mathrm{SD}$ ) of $C$. gigas larvae fed with different diets. Initial shell length $=82.5 \pm 2.5$ $\mu \mathrm{m}$. Values within the same column sharing a common superscript letter are not significantly different $(P>0.05)$

\begin{tabular}{lcccc}
\hline \multirow{2}{*}{ Diet } & \multicolumn{2}{c}{ First week } & \multicolumn{2}{c}{ Second week } \\
\cline { 2 - 5 } & $\begin{array}{c}\text { Shell length } \\
(\mu \mathrm{m})\end{array}$ & $\begin{array}{c}\text { Survival } \\
(\%)\end{array}$ & $\begin{array}{c}\text { Shell length } \\
(\mu \mathrm{m})\end{array}$ & $\begin{array}{c}\text { Survival } \\
(\%)\end{array}$ \\
\hline $\mathrm{P}_{\mathrm{C}}+\mathrm{C}$ & $104.6 \pm 5.7^{\mathrm{a}}$ & $95.9 \pm 1.0^{\mathrm{a}}$ & $48.6 \pm 16.3^{\mathrm{a}}$ & $92.7 \pm 0.5^{\mathrm{ab}}$ \\
$\mathrm{P}_{\mathrm{Fb}}+\mathrm{C}$ & $99.5 \pm 7.8^{\mathrm{a}}$ & $96.3 \pm 0.5^{\mathrm{a}}$ & - & - \\
$\mathrm{P}_{\mathrm{Fsc}}+\mathrm{C}$ & - & - & $144.5 \pm 19.3^{\mathrm{ab}}$ & $89.6 \pm 0.5^{\mathrm{b}}$ \\
$\mathrm{C}$ & $114.3 \pm 8.7$ & $95.1 \pm 0.3^{\mathrm{a}}$ & $139.8 \pm 21.4^{\mathrm{b}}$ & $94.6 \pm 0.3^{\mathrm{a}}$ \\
& & & & \\
Unfed & $86.4 \pm 3.4$ & $95.8 \pm 1.2^{\mathrm{a}}$ & $86.6 \pm 3.1$ & $72.3 \pm 2.0$ \\
\hline
\end{tabular}

$\mathrm{P}_{\mathrm{C}}+\mathrm{C}=P$. lutheri produced in carboys $+C$. calcitrans $\mathrm{f}$. pumilum;

$\mathrm{P}_{\mathrm{FB}}+\mathrm{C}=P$. lutheri produced in FAP in batch mode $+C$. calcitrans $\mathrm{f}$. pumilum;

$\mathrm{P}_{\mathrm{sc}}+\mathrm{C}=P$. lutheri produced in FAP in semi-continuous mode $+C$. calcitrans $\mathrm{f}$. pumilum; $\mathrm{C}=$ C. calcitrans $\mathrm{f}$. pumilum;

Unfed $=$ starved larvae 


\section{Figures}

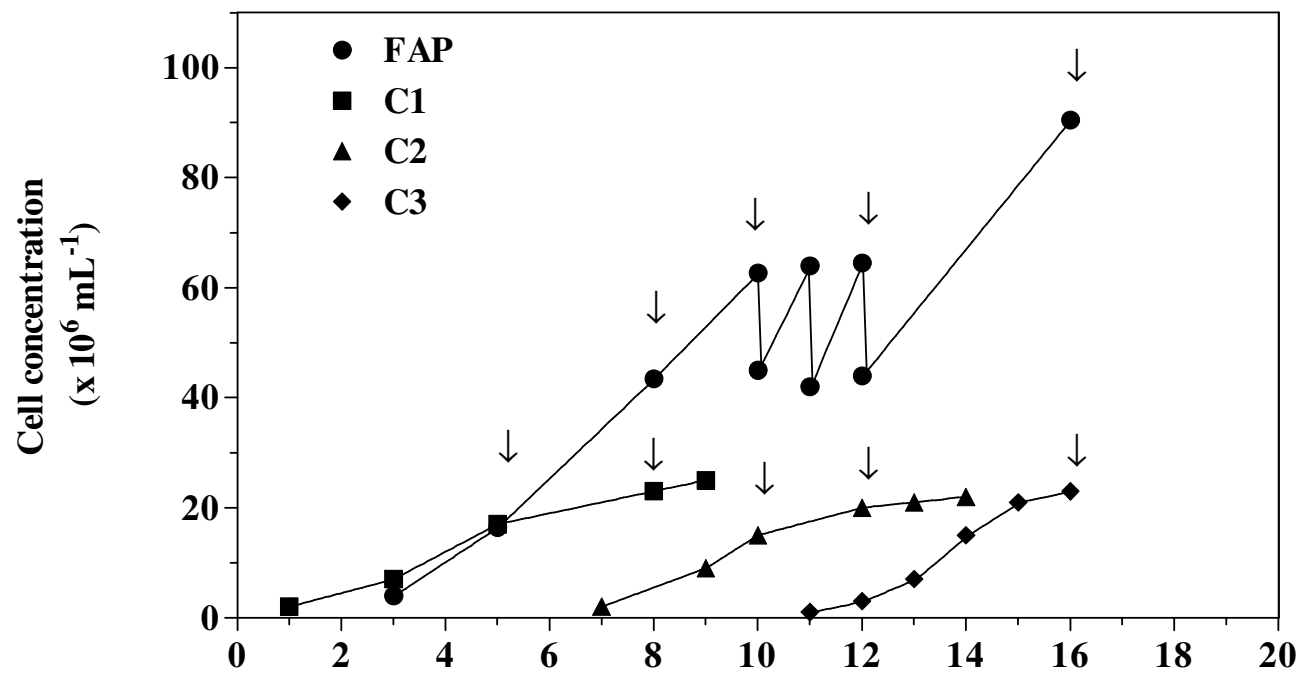

Time (day)

Figure 1 Growth of $P$. lutheri cultivated in a flat alveolar photobioreactor (FAP) or in glass carboys (C1, C2, C3). Arrows indicate the sampling dates for the biochemical analysis and biomass collection for feeding trials. 